This is the author's final, peer-reviewed manuscript as accepted for publication. The publisher-formatted version may be available through the publisher's web site or your institution's library.

\title{
The impact of advanced analytics and data accuracy on operational performance: a contingent resource based theory (RBT) perspective
}

Bongsug (Kevin) Chae, Chenlung Yang, David Olson, Chwen Sheu

\section{How to cite this manuscript}

If you make reference to this version of the manuscript, use the following information:

Chae, B., Yang, C., Olson, D., \& Sheu, C. (2014). The impact of advanced analytics and data accuracy on operational performance: A contingent resource based theory (RBT) perspective. Retrieved from http://krex.ksu.edu

\section{Published Version Information}

Citation: Chae, B., Yang, C., Olson, D., \& Sheu, C. (2014). The impact of advanced analytics and data accuracy on operational performance: A contingent resource based theory (RBT) perspective. Decision Support Systems, 59, 119-126.

Copyright: ( 2013 Elsevier B.V.

Digital Object Identifier (DOI): doi:10.1016/j.dss.2013.10.012

Publisher's Link: http://www.sciencedirect.com/science/article/pii/S0167923613002595

This item was retrieved from the K-State Research Exchange (K-REx), the institutional repository of Kansas State University. K-REx is available at http://krex.ksu.edu 


\title{
The Impact of Advanced Analytics and Data Accuracy on Operational Performance: A Contingent Resource Based Theory (RBT) Perspective
}

\begin{abstract}
This study is interested in the impact of two specific business analytic (BA) resourcesaccurate manufacturing data and advanced analytics - on a firms' operational performance. The use of advanced analytics, such as mathematical optimization techniques, and the importance of manufacturing data accuracy have long been recognized as potential organizational resources or assets for improving the quality of manufacturing planning and control and of a firms' overall operational performance. This research adopted a contingent resource based theory (RBT), suggesting that the moderating and mediating role of fact-based SCM initiatives as complementary resources. This research proposition was tested using Global Manufacturing Research Group (GMRG) survey data and was analyzed using partial least squares/structured equation modeling. The research findings shed light on the critical role of fact-based SCM initiatives as complementary resources, which moderate the impact of data accuracy on manufacturing planning quality and mediate the impact of advanced analytics on operational performance. The implication is that the impact of business analytics for manufacturing is contingent on contexts, specifically, the use of fact-based SCM initiatives such as TQM, JIT, and statistical process control. Moreover, in order for manufacturers to take advantage of the use of data and analytics for better operational performance, complementary resources such as factbased SCM initiatives must be combined with BA initiatives focusing on data quality and advanced analytics.
\end{abstract}

Keywords: Supply Chain Analytics, Data Accuracy, SCM Initiatives, Moderating Effect, Mediating Effect 


\section{The Impact of Advanced Analytics and Data Accuracy on Operational Performance: A Contingent Resource Based Theory (RBT) Perspective}

\section{Introduction}

There is growing interest in the use of data and advanced analytics for various types of business problems (Delen et al. 2012; Turban et al. 2011). Business Analytics (BA) is an umbrella industry term referring to the application of a broad range of analytical techniques and methods and data-driven analytic methodologies to different business domains. The 2011 annual Gartner survey of IT executives shows that BA is \#1 in CIOs' top ten priorities (Thibodeau 2012). Anecdotal evidence and industry press suggest a strong positive relationship between the use of BA and organizational and financial performance (Davenport et al. 2007; Informs 2013). There has long been interest in BA in manufacturing (and supply chain), where it is expected to make significant contributions (Brown et al. 2011; Davenport et al. 2011). Recent studies investigating the role and impact of BA for supply chain management indicate that the use of analytics is positively associated with firm performance (O'Dwyer et al. 2011; Trkman et al. 2010).

This study is interested in the impact of two specific BA resources-accurate manufacturing data and advanced analytics - on manufacturers' operational performance. The use of advanced analytics, such as mathematical optimization techniques (Shapiro 2007; Singh 2003), and the importance of manufacturing data accuracy (Dionne et al. 2011; Huner et al. 2011), have been recognized as potential organizational resources or assets for improving the quality of manufacturing planning and control (MPC) and a firms' overall operational performance.

This study takes a contingent resource based theory (RBT) perspective, suggesting that the impact of primary resources on firm performance is contingent upon complementary resources. What resources are primary is context dependent. In the IS literature, for example, ITs are treated as primary resources (e.g., Luo et al. 2012). In the BA contexts, data and analytics are discussed as two most important elements (Davenport et al. 2011; Delen et al. 2012; O'Dwyer et al. 2011; Sharma et al. 2010). Thus, advanced analytics and accurate manufacturing data are considered two "primary" resources for the use of BA for manufacturing. Complementary resources are those that are expected to 
interact with and increase the value of the primary resources (c.f. Ennen et al. 2010). Our study considers SCM initiatives or programs as complementary resources. By SCM initiatives, we consider such programs as JIT, TQM, and statistical process control, which are aiming for improving operational efficiency through analytical performance improvement techniques and methods. SCM initiatives are considered "complementary" since they are expected to be interacting with and further increasing the value of manufacturing data and analytics.

The primary research goal is to investigate the role of those complementary resources by testing the mediating and moderating effect of SCM initiatives in the impact of primary resources (advanced analytics and manufacturing data accuracy) on operational performance. The study uses the data of 533 samples from Global Manufacturing Research Group (GMRG) survey (Whybark et al. 2009), and employs structured equation modeling (SEM)-partial least squares (PLS) to test the premises. In addition, we conduct a multi-group analysis using three subsample groups depending on firm sizes (small, medium, and large).

The study obtains several important findings. First, high data accuracy improves the perceived quality of manufacturing-related plans (e.g., material, inventory, shop floor), which is positively associated with operational performance. Second, the impact of data accuracy is moderated by the use of SCM initiatives. This implies that, while there is much discussion in the literature about the importance of data accuracy, its impact is contingent upon how extensively SCM initiatives, such as JIT, TQM, and statistical process control, are deployed. Third, the use of advanced analytics positively influences operational performance, but its impact is indirect and transmitted through those SCM initiatives. Fourth, a multi-group analysis indicates that there are no significant differences in path coefficients in the PLS model with different sub-sample groups depending on firm sizes.

The research questions and findings are important, since interest in using data and manufacturing analytics for organizational competitiveness, and the relevant investments, is growing among manufacturers. The research findings imply that, in order for manufacturers to take advantage of the use of data and manufacturing analytics for better operational performance, SCM initiatives must be considered an integral part of the firm's investment in BA initiatives.

\section{Background}

\subsection{A Contingent Resource-Based Theory}


The resource-based theory (RBT) states that organizational resources or assets vary across firms and they differentiate firms' performance and competitive advantage (Barney 1991). RBT has been one of the most prominent and powerful theories in the business literature (Barney et al. 2011). In the literature, there are numerous examples of organizational resources, which include enterprise information systems, knowledge representations and processes, and organizational information (Holsapple et al. 2012; Kim et al. 2012; Luo et al. 2012). Studies have tried to explain why some resources are effective in certain contexts, but not in others. For example, while IT has been recognized in the literature as an important resource, empirical results have been mixed regarding the impact of IT on firms' performance and competitive advantage (Wade et al. 2004). In response, recent studies include contingent variables or complementary resources as necessary elements in their research model (Aragon-Correa et al. 2003; Brush et al. 1999; Harrison et al. 2001). After reviewing IS research using RBT, Wade and Hulland (2004) noted that "resources rarely act alone in creating or sustaining competitive advantage" ( $\mathrm{p}$. 123). This leads to paying attention to the role of other resources or complementary resources, which are linked to primary resources in creating sustainable business value. It is expected that there are synergies from primary and complementary resources (Melville et al. 2004). For example, Kim et al. (2012) considered information resources, analytical and operational capabilities, and human resources as organizational resources, and their study suggested integrating them as a critical factor for CRM success.

As to the role of complementary resources in this synergy-making process, some studies have proposed a moderating effect of complementary resources (Wade et al. 2004). In this line, Luo et al. (2012) considered IT infrastructure, enterprise information systems, and financial resources as firms' resources for improving organizational capabilities, including operational efficiency. The impact of IT assets (IT infrastructure and enterprise information systems) on organizational capabilities is moderated by financial resources: the positive impact of IT assets on organizational capabilities is stronger when firms possess greater financial assets. In addition, mediation has been suggested as another potential role of complementary resources (Kohli et al. 2008). For example, IT and organizational structure as resources positively affect new product 
performance. This process is translated through a mediator or a contingent variable, such as cross-functional integration (Chen 2007). Thus, an RBT-based research model could benefit from considering contingent variables as potential moderators and/or mediators.

\subsection{A Contingent RBT for Analytics}

By applying the concept of contingent RBT into studying the role of business analytics, this study focuses on the effects of data accuracy and advanced analytics. When a contingent RBT is applied in studying the role of business analytics for manufacturing, the focus is on the use of advanced analytics and manufacturing data accuracy. Business analytics is defined as "the extensive use of data, statistical and quantitative analysis, explanatory and predictive models, and fact-based management to drive decision and actions" (Davenport et al. 2007, p. 7). Thus, data accuracy and advanced analytics could be two primary resources. The value of quality data is well recognized in the literature (Redman 1995). "You can't be analytical without data, and you can't be really good at analytics without really good data" (emphasis added) (Davenport et al. 2010, p. 23). There is much promise from using advanced analytics (e.g., mathematical optimization) for manufacturing firms (Chae et al. 2013; O'Dwyer et al. 2011; Singh 2003). This would result in a research model testing the direct impact of data accuracy and advanced analytics on manufacturers' operational performance. However, this approach may find it difficult to explain why some resources are more or less effective in certain situations.

Thus, our research model considers a set of complementary resources, which represent SCM initiatives, such as JIT, TQM, and statistical process control. These increasingly popular SCM programs are examples of fact-based management initiatives in manufacturing firms (Kannan et al. 2005; Kaynak et al. 2008; Nair 2006). The premise of a contingent RBT for business analytics is that the role of such analytic resources as data accuracy and advanced analytics is contingent upon a set of complementary resources. It is expected that when accurate data and advanced analytics are complemented with fact-based SCM initiatives, the value of accurate data would be realized through improved manufacturing planning quality, and the use of advanced analytics can achieve the increase in operational efficiency.

\section{Research Model}


Our research model examines the role of moderation and mediation in the impact of accurate manufacturing data and advanced analytics in operational efficiency. First, a moderator is defined as a variable that "affects the direction and/or strength of the relation between an independent or predictor variable and a dependent or criterion variable" (Baron et al. 1986, p. 1174). The idea of moderating effect is related to the premise of contingency theory that the effect of $\mathrm{X}$ variable on $\mathrm{Y}$ variable can be stronger or weaker, depending on other factors, which are moderators. A moderator influences the strength of the impact of X on Y (Henseler et al. 2010). Thus, it addresses "when" the effect occurs (Baron et al. 1986).

For example, the impact of information content quality and information access quality on the use of information in business processes is contingent upon analytical decision-making culture, which is a moderator (Popovic et al. 2012). Similarly, the higher IS support and business process orientations in an organization, the stronger the impact of analytics on organizational performance (Trkman et al. 2010). The effect of supply chain analytic IT on organizational performance is contingent upon environmental uncertainty (Davis-Sramek et al. 2010).

In the literature, quality data are considered to be important organizational resources or assets (Chae et al. 2013; Redman 1995), impacting organizational performance (Forslund et al. 2007; Gorla et al. 2010). Poor data quality is costly, having consequences on decision making and operation (Redman 1998). In SCM contexts, data is the input to the MPC process. Thus, poor data, which is often characterized by lack of information management and of advanced planning IT, can have far-reaching negative impacts on manufacturing planning (Gustavsson et al. 2008). On the other hand, accurate data is necessary for effective decision making and planning in manufacturing (Dionne et al. 2011; Forslund et al. 2007; Gustavsson et al. 2009; Petersen et al. 2005). This leads us to posit that quality data is positively associated with the quality of manufacturing planning. Manufacturing planning (and scheduling) significantly influences operational performance (De Snoo et al. 2011; Vollmann et al. 2005). Thus, we propose:

Hypothesis 1: Data accuracy improves manufacturing planning quality, which is positively related to operational performance. 
We also believe that the positive effect of quality data on manufacturing planning is strengthened when SCM initiatives are combined. Data and business processes are closely connected: processes use existing data and also create new data (Redman 1995). Thus, there is an interactional effect of data and process improvement on manufacturing planning. SCM initiatives (e.g., statistical process control) are fact-based, analytical techniques and tools focusing on manufacturing process improvement. This leads us to posit that SCM initiatives can be an important contingent variable when firms exploit their data for operation. This indicates the moderating role of fact-based SCM initiatives or programs. On this basis, our second hypothesis is:

Hypothesis 2: SCM initiatives moderate the impact of data accuracy on manufacturing planning quality.

In addition to the moderating effect, we also expect the role of mediation for those SCM initiatives or programs. "A given variable may be said to function as a mediator to the extent that it accounts for the relation between" X and Y (Baron et al. 1986, p. 1176). A mediator (M) explains "how" or "why" the effect of X occurs on Y (Baron et al. 1986). In other words, a mediator is "a pathway for the effect of a predictor on an outcome" (Hopwood 2007, p. 265).

Testing the existence of mediating effect only makes sense when there is the effect of $X$ on $\mathrm{Y}$. When the condition is met, then additional criterion need to be tested for the mediating effect to exist. With the inclusion of a mediator variable $(\mathrm{M})$ in the model, it needs to be proven that $\mathrm{X}$ affects $\mathrm{M}$ and $\mathrm{M}$ affects $\mathrm{Y}$. Finally, the effect of $\mathrm{X}$ on $\mathrm{Y}$, when $\mathrm{M}$ is added into the model, should be zero or significantly weakened.

There has been a long tradition of research on the use of analytical tools and techniques (e.g., mathematical optimization) for manufacturing (Shapiro 2007). Studies have seen the potential of advanced analytics to improve operational performance. Davenport et al. (Davenport et al. 2011; Davenport et al. 2007) have described several areas (e.g., inventory management, network management) where advanced analytics can benefit companies. Trkman et al. (2010) reported that analytics can support supply chain processes such as plan, source, make, and deliver. In this line of research, Sharma et al. (2010) suggested that there may be an indirect relationship between analytics and performance, noting that analytics enables manufacturers "to apply resources to undertake actions to deliver performance gains and competitive advantage" (p. 
193). The authors also noted the use of analytics in quality and process improvement (Teece et al. 1997), which enhances operational performance.

On this basis and from a contingent RBT perspective, we expect that the impact of advanced analytics on operational performance is mediated through fact-based SCM initiatives. SCM initiatives, such as TQM and statistical process control, are fact-based or analytical methodologies for process and quality improvement. The implementation and effectiveness of those methodologies do not occur in a vacuum. Instead, among others, organizations' analytical capability is considered an enabling condition for the effective implementation of those methodologies.

Hypothesis 3: The positive effect of advanced analytics on operational performance is mediated through SCM initiatives.

A conceptual research model summarizing from the above discussion of moderating effect and mediating effect is presented in Figure 1. In addition to these three hypotheses based on the review of previous studies, our research will also explore the existence of other possible relationships moderated and mediated through SCM initiatives 1 .

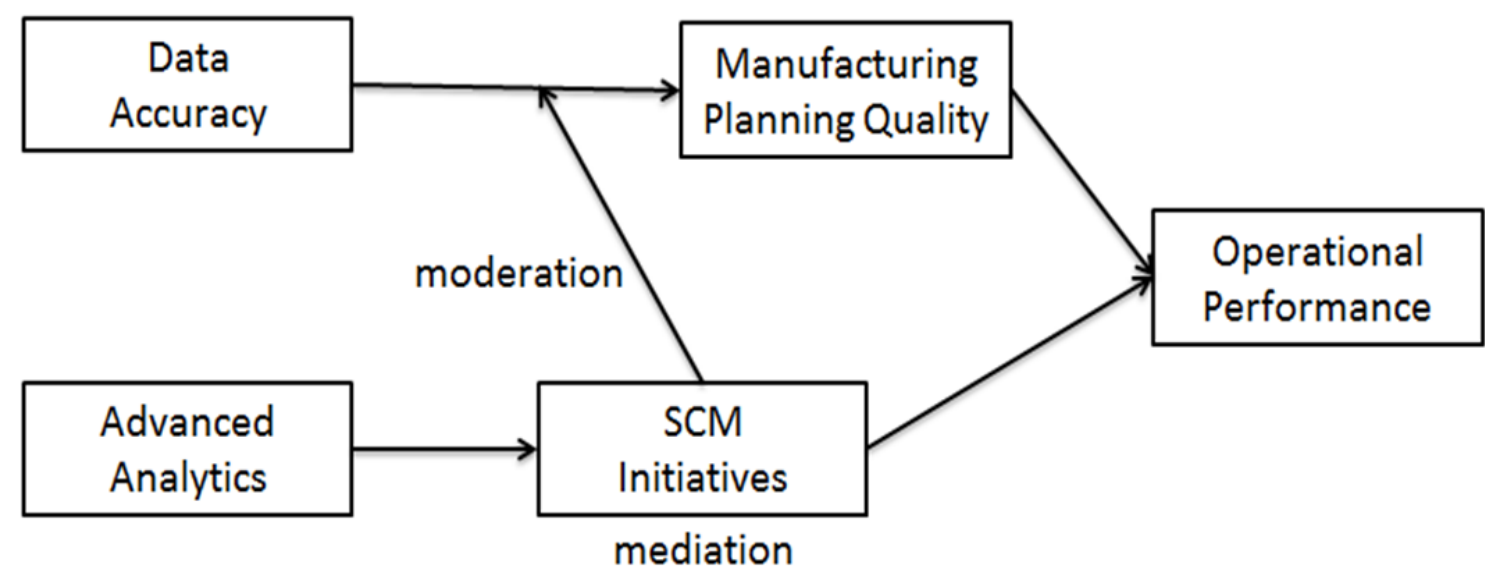

Figure 1. A Conceptual Research Model

4. Research Methodology

\subsection{Data Source}

\footnotetext{
${ }^{1}$ We thank an anonymous reviewer for suggesting this. We acknowledge that this has led to offering additional insights, which are reported in Sections 5.2 and 6.
} 
The data were a sub-sample of the Round IV GMRG data collection effort. The Global Manufacturing Research Group (GMRG) (www.gmrg.org) is an international community of researchers studying the improvement of manufacturing supply chains worldwide. The GMRG consists of leading international academic researchers from over 20 countries. These researchers developed the GMRG survey instrument to understand manufacturing and supply chain practices around the world. This survey instrument facilitates a global comparison of the effectiveness of manufacturing and supply chain practices (Whybark et al. 2009). Since 1985, the GMRG has completed three rounds of the worldwide survey and is currently completing the fourth round. The survey questionnaires for all countries were translated and back-translated by several academic researchers.

This study uses the data from the Round 4.0 GMRG Survey, with 533 samples from 15 countries and 14 industry classifications (See Appendix Table A.1 for distribution statistics). The GMRG questionnaire consists of two parts (Whybark et al. 2009). The first part is the background section on company demographics, manufacturing practices, competitive goals, and internal performance. The second part contains four optional modules addressing specific management issues: Manufacturing Information Systems MIS), Outsourcing, Purchasing, and Forecasting. Among them, the background section, the MIS module, and the Outsourcing module provide specific information pertaining to the research objectives of this study, such as data accuracy, data analysis, quality of manufacturing planning, operational performance, organizational processes, and business analytics. The survey questionnaire was previously validated in many studies published in top journals, including Journal of Operations Management, Decision Sciences, among others. The breadth and depth of the data indicate the generalizability of the results (Bunge 1967; Wacker 1998), and there have been many studies using this data set, published in top-tier journals.

\subsection{Constructs}

The research design includes five constructs. Data accuracy (DA) and advanced analytics (AA) are constructed related to two primary resources of business analytics for manufacturing. SCM initiatives (SCI) serve as a construct of moderator and mediator representing 
complementary resources. Manufacturing planning quality (MPQ) and operational performance (OP) are two dependent constructs (see Appendix B for further details).

Data accuracy (DA): Data is key for manufacturing-related decision making and planning (Shang et al. 2008). There are diverse sets of production and supply chain planning data required for planning, including inventory records (Dionne et al. 2011). Data accuracy is measured by survey assessed accuracy level of three types of data: inventory records, plants' bills of material, and routings.

Advanced analytics (AA): This AA construct is a measure for how analytical a firm becomes in manufacturing-related decisions. There are different measurements for assessing the level of analytical capabilities of a manufacturer in previous studies (Trkman et al. 2010). For example, Davis-Sramek et al. (2010) used the level of analytical IT use. We consider three methods as primary ways for data analysis: experience, statistical methods, and mathematical optimization. These three methods represent three levels of advanced analytics (experience as basic; statistical methods as intermediate; mathematical optimization as advanced).

SCM initiatives or programs (SCI): The literature shows that manufacturers have adopted diverse process and quality programs to improve operational performance. These programs tend to be fact-based, in that manufacturing data are used for performance evaluation and control (Kannan et al. 2005; Kaynak et al. 2008; Nair 2006). In this study, SCI is represented by the extent of organizational investment in three such practices: just in time, total quality management, and statistical process control.

Manufacturing planning quality (MPQ): The quality of manufacturing planning is important for improving operational performance. Perceived quality of manufacturing planning is used in this study. MPQ is measured by the extent of satisfaction on five types of manufacturing planning: material planning, inventory control, labor planning, shop floor control, and cost planning (Wacker et al. 2006).

Operational performance (OP): OP represents manufacturers' operational performance. Manufacturers have used diverse measurements for operational performance (Vollmann et al. 2005). We use five performance-related measurements: order fulfillment, delivery as promised, delivery flexibility, and flexibility to change product mix and flexibility to change output volume. 


\section{Model Analysis}

Business analytics for manufacturing is increasingly becoming an important practice in industry and a research topic in academia. There are two primary resources related to this business practice: accurate data and advanced analytics. This research takes a contingent RBT perspective on the effect of these resources on operational performance. The proposed approach focuses on the moderating and mediating roles of SCM initiatives or programs. Thus, this research is exploratory, rather than confirmatory in nature, and focuses on understanding the relationships between business analytics-related resources and manufacturing operational performance. Partial Least Squares (PLS) is suitable for this type of research (Gefen et al. 2011; Hair et al. 2011; Peng et al. 2012). WarpPLS software was used in this model analysis. Below, we report evaluation of individual measurements and evaluation of the overall PLS model.

\subsection{Measure Evaluation}

For reliability, we assess composite reliability and combined item loading scores. The composite reliability coefficients of all constructs (Table 1 ) are greater than 0.80 , indicating acceptable reliability (Fornell et al. 1981; Nunnally et al. 1994). Combined loadings for all indicators are greater than 0.70 and significant at the level of 0.001 (Table 1).

Table 1. Composite reliability and average variances extracted (AVE)

\begin{tabular}{|r|r|c|r|r|r|r|r|}
\hline $\begin{array}{l}\text { Composite } \\
\text { Reliability }\end{array}$ & AVE & & DA & MPQ & \multicolumn{1}{c|}{ SCI } & \multicolumn{1}{c|}{ AA } & \multicolumn{1}{c|}{ OP } \\
\hline 0.915 & 0.783 & DA & $\mathbf{0 . 8 8 5}$ & 0.147 & 0.000 & 0.064 & 0.063 \\
\hline 0.910 & 0.670 & MPQ & 0.147 & $\mathbf{0 . 8 1 9}$ & 0.339 & 0.238 & 0.212 \\
\hline 0.819 & 0.602 & SCI & 0.000 & 0.339 & $\mathbf{0 . 7 7 6}$ & 0.252 & 0.313 \\
\hline 0.891 & 0.731 & AA & 0.064 & 0.238 & 0.252 & $\mathbf{0 . 8 5 5}$ & 0.069 \\
\hline 0.903 & 0.651 & OP & 0.063 & 0.212 & 0.313 & 0.069 & $\mathbf{0 . 8 0 7}$ \\
\hline
\end{tabular}

Note: Square roots of average variances extracted (AVE's) shown on diagonal.

To assess the validity of each construct, we use the square root of the average variance extracted (AVE). The AVE values for all constructs are greater than 0.50 , indicating convergent validity at the construct level. Each indicator's loading is higher than its cross loadings (Chin 2010; Hair et al. 2011) (Table 2) and the square root of every AVE is much higher than any correlation between the construct and other constructs (Gefen et al. 2000) (Table 1), indicating discriminant validity. 
Table 2. Loadings and cross-loadings

\begin{tabular}{|l|l|l|l|l|l|l|}
\hline Item & AA & DA & MPQ & SCI & OP & P value \\
\hline AA_1 & $\mathbf{0 . 8 5 0}$ & 0.010 & 0.004 & 0.006 & -0.087 & $<0.001$ \\
\hline AA_2 & $\mathbf{0 . 8 7 1}$ & -0.014 & 0.007 & 0.025 & 0.028 & $<0.001$ \\
\hline AA_3 & $\mathbf{0 . 8 4 3}$ & 0.004 & -0.011 & -0.032 & 0.059 & $<0.001$ \\
\hline DA_1 & 0.004 & $\mathbf{0 . 9 1 3}$ & -0.001 & -0.075 & -0.011 & $<0.001$ \\
\hline DA_2 & -0.053 & $\mathbf{0 . 9 3 4}$ & 0.012 & -0.022 & 0.003 & $<0.001$ \\
\hline DA_3 & 0.058 & $\mathbf{0 . 8 0 2}$ & -0.013 & 0.112 & 0.010 & $<0.001$ \\
\hline MPQ_1 & -0.039 & 0.065 & $\mathbf{0 . 8 2 0}$ & 0.009 & 0.010 & $<0.001$ \\
\hline MPQ_2 & -0.024 & 0.042 & $\mathbf{0 . 8 1 0}$ & -0.027 & 0.044 & $<0.001$ \\
\hline MPQ_3 & 0.055 & -0.012 & $\mathbf{0 . 8 4 0}$ & -0.078 & 0.002 & $<0.001$ \\
\hline MPQ_4 & 0.036 & -0.033 & $\mathbf{0 . 8 1 8}$ & 0.026 & -0.042 & $<0.001$ \\
\hline MPQ_5 & -0.031 & -0.062 & $\mathbf{0 . 8 0 5}$ & 0.073 & -0.014 & $<0.001$ \\
\hline SCI_1 & -0.087 & -0.035 & 0.053 & $\mathbf{0 . 7 9 5}$ & 0.072 & $<0.001$ \\
\hline SCI_2 & 0.130 & 0.100 & -0.068 & $\mathbf{0 . 7 8 4}$ & -0.107 & $<0.001$ \\
\hline SCI_3 & -0.044 & -0.067 & 0.015 & $\mathbf{0 . 7 4 7}$ & 0.036 & $<0.001$ \\
\hline OP_1 & -0.008 & -0.072 & 0.034 & 0.052 & $\mathbf{0 . 8 0 5}$ & $<0.001$ \\
\hline OP_2 & 0.018 & -0.077 & 0.055 & 0.010 & $\mathbf{0 . 7 8 5}$ & $<0.001$ \\
\hline OP_3 & -0.021 & 0.017 & -0.026 & -0.048 & $\mathbf{0 . 8 5 3}$ & $<0.001$ \\
\hline OP_4 & 0.010 & 0.072 & -0.039 & 0.049 & $\mathbf{0 . 8 2 6}$ & $<0.001$ \\
\hline OP_5 & 0.002 & 0.059 & -0.021 & -0.065 & $\mathbf{0 . 7 6 1}$ & $<0.001$ \\
\hline
\end{tabular}

\subsection{Evaluation of the PLS-SEM Model}

First, we assess the moderating effect of SCM initiatives between data accuracy (DA) and manufacturing planning quality (MPQ). PLS analysis shows that DA is positively associated with MPQ and there are moderating effects $(\beta=0.21 \mathrm{p}=0.01)$ of fact-based SCM initiatives (SCI) such as TQM, JIT, and statistical process control (Figure 2). This confirms the role of SCI as a moderator, but the effect size seems small as indicated by relatively low R-squares. After this confirmation, we extended our analysis to see if the moderation of SCI is, in fact, "mediated moderation". Mediated moderation takes places when four variables are interacting through moderation and mediation in that the interaction effect of an independent variable and a moderator on the dependent variable is through a mediator (Bucy et al. 2007; Muller et al. 2005). The result indicates the presence of a mediated moderation. That is, the interacting effect of data accuracy and SCI initiatives is transmitted to operational performance through manufacturing planning quality. 
Second, studying the mediating effect requires two separate models. One model is designed with only two constructs: advanced analytics (AA) and operational performance (OP). The PLS analysis shows that there is a significant relationship $(\beta=0.12 \mathrm{p}=0.04)$ between advanced analytics and operational performance at the level of 0.05 . With this finding, which validates the further analysis for mediation, another model is developed with a third construct (SCI). The analysis indicates that when SCI is added as a mediator between AA and OP, the direct impact of AA on OP becomes non-significant $(\beta=0.02 p=0.37)$ and SCI plays the role of mediator between the two constructs. We also tested the mediating impact of SCI using the Sobel test and through the estimation of indirect effects (Kock 2013). The outcomes confirm the mediating role of SCI.

Figure 2 shows the complete PLS model and its results. Table 3 presents the results of testing three hypotheses. In summary, data accuracy increases manufacturing planning quality, which subsequently improves manufacturing operational performance. There is no direct relationship between data accuracy and operational performance. Additionally, the positive impact of data accuracy on planning quality is greater when resources such as SCM initiatives are invested. Advanced analytics makes a positive contribution to operational performance. But its impact is indirect, through SCM initiatives as a mediator.

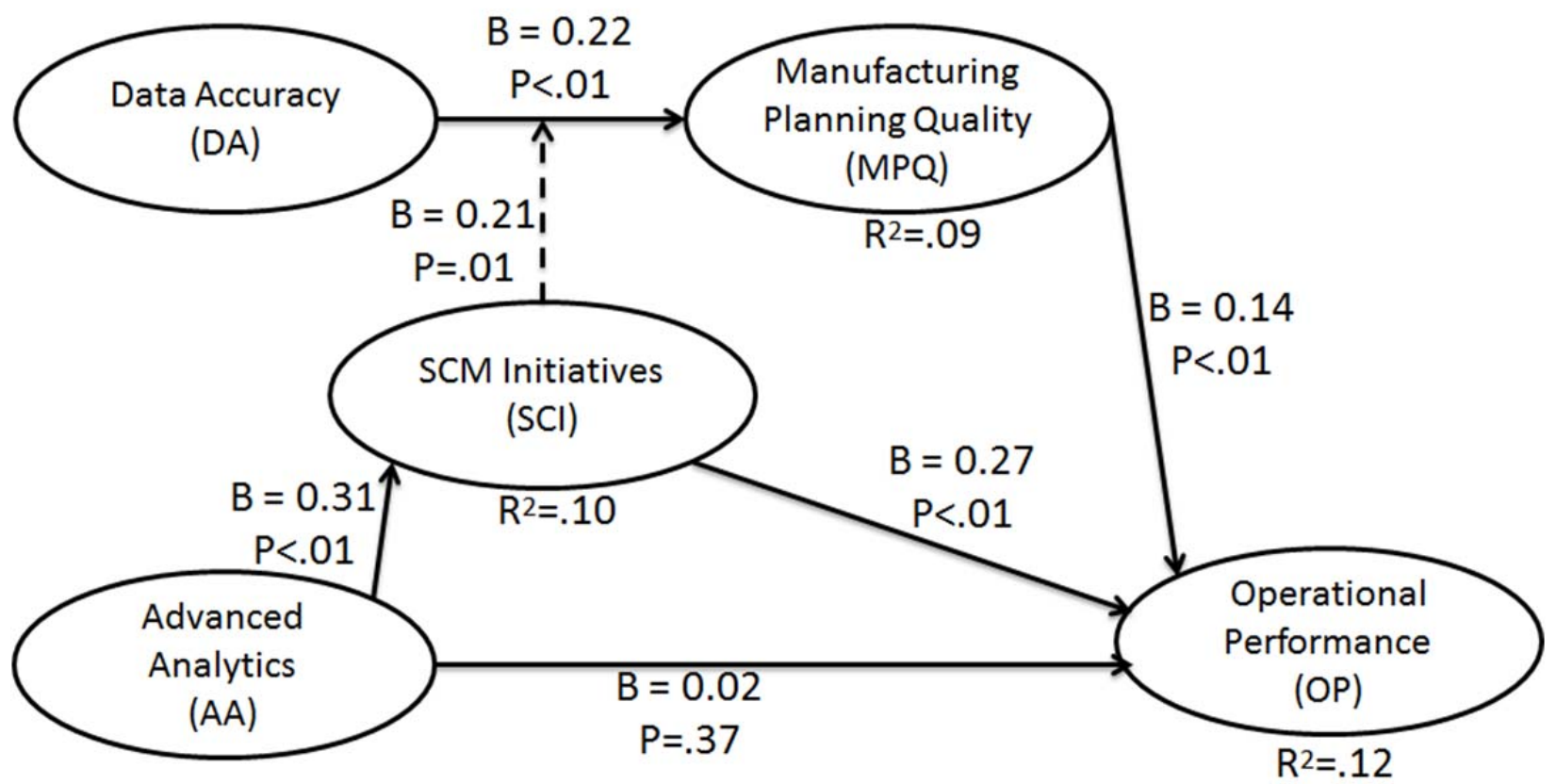

Figure 2. The Complete Results 
Table 3. The Results of Testing Hypotheses

Hypothesis 1: Data accuracy improves manufacturing planning quality, which is positively related to operational performance.

Hypothesis 2: SCM initiatives moderate the impact of data accuracy on manufacturing planning quality.

Hypothesis 3: The positive effect of advanced analytics on operational performance is mediated through SCM initiatives.

Supported

Supported

Supported

We continued our analysis using a multi-group analysis. For this, we divided the data into subsamples depending company size. Our multi-group analysis focused on three subsamples-(1) small firm size, (2) medium firm size and (3) large firm size. The sample sizes are 115, 206, and 212 respectively (see Appendix A). Our analysis produced a t-statistic and $p$ values using the sample sizes, coefficients of the relationships, and standard errors (see Table 4). The results of tstatistics and $p$ values indicate that there is no statistical significance of difference in these three groups.

Table 4. The Results of A Multi-group Analysis Depending on Firm Size

\begin{tabular}{|c|r|r|r|r|r|r|}
\hline \multirow{2}{*}{ Relationships } & \multicolumn{2}{|c|}{ Small vs. Medium Size } & \multicolumn{2}{c|}{ Small vs. Large Size } & \multicolumn{2}{c|}{ Medium vs. Large Size } \\
\cline { 2 - 7 } & $\mathbf{t}$-statistic & \multicolumn{1}{c}{$\mathbf{p}$} & t-statistic & $\mathbf{p}$ & t-statistic & \multicolumn{1}{c|}{$\mathbf{p}$} \\
\hline AA-OP & 0.277 & 0.782 & 1.002 & 0.317 & 1.419 & 0.157 \\
\hline AA-SCI & 0.070 & 0.944 & 0.062 & 0.951 & 0.010 & 0.992 \\
\hline DA-MPQ & 0.886 & 0.376 & 0.803 & 0.422 & 0.227 & 0.821 \\
\hline SCI-OP & 0.645 & 0.519 & 0.058 & 0.954 & 0.688 & 0.492 \\
\hline MPQ-OP & 1.591 & 0.113 & 1.756 & 0.080 & 0.827 & 0.409 \\
\hline SCI*DA & 0.976 & 0.330 & 0.301 & 0.763 & 1.031 & 0.303 \\
\hline
\end{tabular}

Next, we extended our analysis into exploring the existence of other possible moderated or mediated relationships among the constructs through SCM initiatives. We specifically looked at the significance of the following moderated and mediated relationships in our analysis: 
\#1: SCM initiatives (SCI) moderate the impact of data accuracy (DA) on operational performance (OP).

\#2: SCM initiatives moderate the impact of advanced analytics (AA) on operational performance.

\#3: SCM initiatives moderate the impact of advanced analytics on manufacturing planning quality.

\#4: The effect of advanced analytics on manufacturing planning quality (MPQ) is mediated through SCM initiatives.

\#5: The effect of data accuracy on operational performance is mediated through SCM initiatives.

\#6: The effect of data accuracy on manufacturing planning quality is mediated through SCM initiatives.

To test these relationships, we expanded the original research model by including 6 additional relationships. The full dataset (533 samples) was used in this analysis. The results of testing this expanded model show that only the mediating role of SCM initiatives in the impact of advanced analytics on manufacturing planning quality (\#4) is found to be statistically significant. AA is positively associated with MPQ $(\beta=0.24 \mathrm{p}<0.01)$. When SCI is added as a mediator, the relationship between AA and MPQ becomes weaker $(\beta=0.13 \mathrm{p}<0.01)$, while the relationships (AA $\rightarrow$ SCI and SCI $\rightarrow$ MPQ) are found to be statistically significant. On the other hand, none of the other relationships $(\# 1, \# 2, \# 3, \# 5$, and \#6) were found to be statistically significant.

\section{Discussion and Implications}

There is an increasing interest in the extensive use of data and analytical techniques and tools for business, broadly known as business analytics. Recent studies have suggested the business value of data and analytics for manufacturing (Davenport et al. 2011; O'Dwyer et al. 2011; Oliva et al. 2011; Trkman et al. 2010). Our research supports that accurate manufacturing data and advanced analytics could be valuable resources for creating business value, specifically improving manufacturers' operational performance. 
First, data is considered important for business (Redman 1995) and a key building block of business analytics for manufacturing. Quality data is also an indicator of firms' analytical maturity (Popovic et al. 2012). This study finds that accurate manufacturing data can increase the quality of manufacturing planning. This confirms findings of previous studies that manufacturing data and their quality are important for SCM (Chae et al. 2013; Huner et al. 2011), and planning quality positively contributes to operational performance (De Snoo et al. 2011; Vollmann et al. 2005). In addition, our findings shed light on the moderating role of SCM initiatives. When manufacturers combine accurate data with complementary resources, such as TQM, JIT, and statistical process control, they are able to enhance the business value of accurate data for manufacturing planning quality. Our extended analysis also indicates there is mediated moderation. That is, for the manufacturers with high SCM initiatives, data accuracy leads to increased manufacturing planning quality, which subsequently improves operational performance.

Second, in recent years the use of advanced analytics has been echoed in academic literature and industry press. Previous studies suggest that firms can create business value from the adoption of advanced analytics (Brynjolfsson et al. 2011; Davenport et al. 2010). Some have found that there is a direct positive relationship between advanced analytics and operational performance. For example, the use of analytics for SCM processes such as plan, source, make, and delivery, was found to be positively associated with operational performance (Trkman et al. 2010). However, our finding indicates there could also be an indirect relationship between analytics and organizational performance. Specifically, the positive impact of advanced analytics on operational performance is fully mediated through the adoption of fact-based SCM initiatives. When SCM initiatives (SCI) were included in the PLS model, the relationship between advanced analytics (AA) and operational performance (OP) dropped to almost zero. This explains how and why advanced analytics positively impacts operational performance. The use of advanced analytics as the primary way of determining manufacturing data is likely to increase the adoption of fact-based or analytical SCM programs (e.g., JIT, statistical process control). In turn, these practices make a positive impact on operational performance (Kannan et al. 2005; Rungtusanatham 2001).

According to multi-group analysis, which was reported earlier in Section 5, there are no statistically significant differences in the path coefficients regardless of firm size. In addition, our 
extended analysis of testing additional moderated and mediated relationships through SCM initiatives (SCI) shows that SCI carries the mediating role between advanced analytics (AA) and manufacturing planning quality (MPQ). This suggests that the use of advanced analytics positively contributes to the planning quality and its impact is partially transmitted through SCM initiatives.

The findings from this research can be useful for practice and research as the volume of manufacturing-related data and the power of analytical tools are growing at a high speed. For practice, our research findings imply that BA projects for manufacturing must consider the investment, not only in primary resources such as data (and data quality) and advanced analytics (e.g., mathematical optimization techniques), but also in complementary resources, specifically, analytical performance management programs. These programs need to be combined with quality data and advanced analytical capabilities in an integrated way. Without those complementary resources, the promises of such primary resources as quality data and advanced analytics would not be realized.

For research, in investigating the impact of business analytics most studies have expected the direct impact of data and analytical capabilities on operational and/or financial performance. Our research findings reveal the possibility of complementary resources to play a mediating role, thereby suggesting that the indirect, rather than direct, relationship is a more likely explanation as to the impact of business analytics on manufacturers' operational performance. Ignoring important mediators such as SCM initiatives could lead to a potentially misleading conclusion that the use of advanced analytics alone creates business value and improves operational performance. This further suggests the need of a contingent perspective for studying the value of business analytics, specifically, for manufacturing (and SCM).

Finally, that there is the moderating effect of complementary resources in the impact of accurate data on manufacturing planning quality seems to indicate that it would be possible for manufacturers to consider configuration strategies. For example, the investment in data and IT infrastructure for quality data alone would be an efficient business decision for manufacturers in stable business environments. In contrast, those in dynamic environments would choose to deploy fact-based SCM initiatives along with the investment for accurate data. This further demands the use of contingency (or configuration) theory (El Sawy et al. 2010; Fiss 2007) in studying the value of business analytics. 


\section{Conclusion}

As there is a growing interest in the deployment of business analytics (BA) for manufacturing, it is imperative for firms to understand business values of such investment and for prescribing ways to extract benefits of BA in practice. This study has attempted to address these issues by investigating the impact of two primary BA resources: accurate data and advanced analytics. The research adopted a contingent resource based theory (RBT), suggesting the moderating and mediating role of fact-based SCM initiatives as complementary resources. This research design was tested using Global Manufacturing Research Group (GMRG) survey data and PLS-SEM methods.

The research findings could shed light on the critical role of SCM initiatives as complementary resources, which moderate the impact of data accuracy on manufacturing planning quality and mediate the impact of advanced analytics on operational performance. This indicates that the impact of business analytics for manufacturing is contingent on contexts, specifically, the use of fact-based SCM programs such as TQM, JIT, and statistical process control. These findings imply that, in order for manufacturers to take advantage of the use of data and analytics for better operational performance, complementary resources, such as fact-based SCM initiatives, must be combined with BA initiatives focusing on data quality and analytics. This suggests that future research on BA impact and benefits could further benefit from contingency (or configuration) theory.

In this regard, future studies could benefit from case research in gaining greater understanding of technological and organizational contexts (or contingencies) where business analytics are deployed to improve operational performance. Our research model did not include a control variable(s). Future research could consider such contexts as environmental uncertainty and supply chain complexity as control variables. The present study has used the GRMG survey data to explore a relatively new topic, business analytics for manufacturing operation. We believe it will be a fruitful endeavor to extend this line of research using a first-hand dataset, entirely designed for this increasingly important subject in business. 


\section{Appendix A: Distribution of industries and firm size}

(a) Firm size

\begin{tabular}{|c|c|c|}
\hline Size & Frequency & Percentage \\
\hline (1) $<=50$ employees & 115 & $21.6 \%$ \\
\hline (2) $51-250$ employees & 206 & $38.6 \%$ \\
\hline (3) $>=251$ employees & 212 & $39.7 \%$ \\
\hline Total & 533 & $100.0 \%$ \\
\hline
\end{tabular}

(b) Industry

\begin{tabular}{|l|r|r|l|r|r|}
\hline \multicolumn{1}{|c|}{ Industry } & \multicolumn{1}{|c|}{ Freq. } & Percent & \multicolumn{1}{|c|}{ Industry } & Freq. & Percent \\
\hline Food And Kindred Products & 29 & $5.4 \%$ & $\begin{array}{l}\text { Rubber And Miscellaneous } \\
\text { Plastics Products }\end{array}$ & 19 & $3.6 \%$ \\
\hline Textile Mill Products & 16 & $3.0 \%$ & Primary Metal Industries & 5 & $0.9 \%$ \\
\hline $\begin{array}{l}\text { Apparel and Other finished } \\
\text { Products }\end{array}$ & 9 & $1.7 \%$ & Fabricated Metal Products & 60 & $11.3 \%$ \\
\hline Leather And Leather Products & 5 & $0.9 \%$ & $\begin{array}{l}\text { Industrial And Commercial } \\
\text { Machinery }\end{array}$ & 70 & $13.1 \%$ \\
\hline $\begin{array}{l}\text { Lumber And Wood Products, } \\
\text { Except Furniture }\end{array}$ & 7 & $1.3 \%$ & $\begin{array}{l}\text { Electronic And Other } \\
\text { Electrical Equipment }\end{array}$ & 116 & $21.8 \%$ \\
\hline Paper And Allied Products & 15 & $2.8 \%$ & $\begin{array}{l}\text { Measuring, Analyzing, And } \\
\text { Controlling Instruments }\end{array}$ & 12 & $2.3 \%$ \\
\hline $\begin{array}{l}\text { Printing, Publishing, And Allied } \\
\text { Industries }\end{array}$ & 5 & $0.9 \%$ & $\begin{array}{l}\text { Manufacture of motor } \\
\text { vehicles, trailers and semi- } \\
\text { trailers }\end{array}$ & $\mathbf{7}$ & $1.3 \%$ \\
\hline $\begin{array}{l}\text { Petroleum Refining And Related } \\
\text { Industries }\end{array}$ & 3 & $0.6 \%$ & $\begin{array}{l}\text { Manufacture of other transport } \\
\text { equipment }\end{array}$ & 6 & $1.1 \%$ \\
\hline Chemical and allied products & 14 & $2.6 \%$ & Furniture And Fixtures & 13 & $2.4 \%$ \\
\hline $\begin{array}{l}\text { Miscellaneous Manufacturing } \\
\text { Industries }\end{array}$ & 27 & $5.1 \%$ & $\begin{array}{l}\text { Stone, Clay, Glass, And } \\
\text { Concrete Products }\end{array}$ & 11 & $2.1 \%$ \\
\hline Not Reported & 84 & $15.8 \%$ & Total & 533 & $\mathbf{1 0 0 . 0 \%}$ \\
\hline
\end{tabular}


Appendix B: Detailed information on constructs Construct: DA (Data Accuracy)

1) How accurate are the plant's inventory records?

2) How accurate are the plant's bills of material?

3) How accurate are routings?

\begin{tabular}{|l|l|}
\hline Mean & S.D \\
\hline 0.809 & 0.317 \\
0.810 & 0.323 \\
0.697 & 0.398 \\
\hline
\end{tabular}

\section{Construct: AA (Advanced Analytics)}

1) What is the primary way of determining manufacturing batch sizes?

2) What is the primary way of determining lead times and routings

3) What is the primary way of determining safety stocks and safety lead times?

1: experience /2: Statistical methods / 3:Mathematical optimization

\begin{tabular}{|l|l|}
\hline Mean & S.D \\
\hline 1.747 & 0.767 \\
1.726 & 0.751 \\
1.741 & 0.744 \\
& \\
\hline
\end{tabular}

Construct: SCI (SCM Initiatives)

1) Extent of invested resources in TQM

2) Extent of invested resources in Statistical Process Control

3) Extent of invested resources in JIT

1: not at all - 7: to a great extent

\begin{tabular}{|l|l|}
\hline Mean & S.D \\
\hline 4.595 & 1.689 \\
3.835 & 1.805 \\
3.938 & 1.776 \\
\hline
\end{tabular}

\begin{tabular}{|l|l|l|}
\hline Construct: MPQ (Manufacturing Planning Quality) & Mean & S.D \\
\hline To what extent are you satisfied with your current: & & \\
1) Material Planning & 4.678 & 1.517 \\
2) Inventory Control & 4.784 & 1.539 \\
3) Labor Planning & 4.296 & 1.527 \\
4) Shop Floor Control & 4.495 & 1.508 \\
5) Cost Planning & 4.670 & 1.516 \\
1: very dissatisfied - 7: very satisfied & & \\
\hline
\end{tabular}

\begin{tabular}{|l|l|l|}
\hline Construct: OP (Operational performance) & Mean & S.D \\
\hline Compare the performance with your major competitors & & \\
1) Order Fulfillment & 5.268 & 1.221 \\
2) Delivery As Promised & 5.253 & 1.180 \\
3) Delivery Flexibility & 5.356 & 1.147 \\
4) Flexibility to Change Output Volume & 5.120 & 1.208 \\
5) Flexibility to Change Product Mix & 5.094 & 1.252 \\
1: far worse - 7: far better & & \\
\hline
\end{tabular}




\section{References}

Aragon-Correa, J., and Sharma, S. "A Contingent Resource-Based View of Proactive Corporate Environmental Strategy," Academy of Management Review (28:1) 2003, pp 71-88.

Barney, J. "Firm Resources and Sustained Competitive Advantage," Journal of Management (17:1) 1991, pp 99-120.

Barney, J., Ketchen, D., and Wright, M. "The Future of Resource-Based Theory: Revitalization or Decline?," Journal of Management (37:5) 2011, pp 1299-1315.

Baron, R., and Kenny, D. "The Moderator-Mediator Variable Distinction in Social Psychological Research: Conceptual, Strategic, and Statistical Considerations," Journal of Personality and Social Psychology (51:6) 1986, pp 1173-1182.

Brown, B., Chui, M., and Manyika, J. "Are You Ready for the Era of 'Big Data'?," McKinsey Quarterly (October) 2011, pp 1-12.

Brush, T., and Artz, K. "Toward A Contingency Resource-based Theory: The Impact of Information Asymmetry on the Value of Capabilities in Veterinary Medicine," Strategic Management Journal (20) 1999, pp 223-250.

Brynjolfsson, E., Hitt, L., and Kim, H. "Strength in Numbers: How Does Data-Driven Decisionmaking Affect Firm Performance?," Available at SSRN: http://ssrn.com/abstract=1819486 or http://dx.doi.org/10.2139/ssrn.1819486) 2011.

Bucy, E., and Tao, C. "The Mediated Moderation Model of Interactivity," Media Psychology (9) 2007, pp 647-672.

Bunge, M. Scientific Research Springer-Verlag, Berlin, 1967.

Chae, B., and Olson, D. "Business Analytics for Supply Chain: A Dynamic-Capabilities Framework," International Journal of Information Technology \& Decision Making (12:9) 2013, pp 9-26.

Chen, C. "Information Technology, Organizational Structure, and New Product DevelopmentThe Mediating Effect of Cross-Functional Team Interaction," IEEE Transactions on Engineering Management (54:4) 2007, pp 687-698.

Chin, W. "How to Write Up and Report PLS Analyses," in: Handbook of Partial Least Squares, V. Vinzi (ed.), Springer-Verlag, Berlin, 2010, pp. 655-690.

Davenport, T., Harris, J. G., and Morison, R. Analytics at Work: Smarter Decisions, Better Results Harvard Business Press, Boston, MA, 2010.

Davenport, T., and O'Dwyer, J. "Tap Into the Power of Analytics," Supply Chain Quarterly (Fourth Quarter) 2011, pp 28-31.

Davenport, T. H., and Harris, J. G. Competing on Analytics: The New Science of Winning Harvard Business School Press, Boston, 2007.

Davis-Sramek, B., Germain, R., and Iyer, K. "Supply Chain Technology: The Role of Environment in Predicting Performance," Journal of the Academy of Marketing Science (38) 2010, pp 42-55.

De Snoo, C., Wezel, W., and Jorna, R. "An Empirical Investigation of Scheduling Performance Criteria," Journal of Operations Management (29) 2011, pp 181-193.

Delen, D., and Demirkan, H. "Data, Information and Analytics as Services," Decision Support Systems (In Press) 2012.

Dionne, L., and Kempf, K. "Data in Production and Supply Chain Planning," in: Planning Production and Inventories in the Extended Enterprise, K. Kempf (ed.), Springer, 2011, pp. 167-184. 
El Sawy, O., Malhotra, A., Park, Y., and Pavlou, P. "Seeking the Configurations of Digital Ecodynamics: It Takes Three to Tango," Information Systems Research (21:4) 2010, pp 835-848.

Ennen, E., and Richter, A. "The Whole Is More Than the Sum of Its Parts-Or Is It? A Review of the Empirical Literature on Complementarities in Organizations," Journal of Management (36:1) 2010, pp 207-233.

Fiss, P. "A Set-Theoretic Approach to Organizational Configurations," Academy of Management Review (32:4) 2007, pp 1180-1198.

Fornell, C., and Larcker, D. "Evaluating Structural equation Models with Unobservable Variables and Measurement Error," Journal of Marketing Research (18:1) 1981, pp 3950 .

Forslund, H., and Jonsson, P. "The Impact of Forecast Information Quality on Supply Chain Performance," International Journal of Operations \& Production Management (27) 2007, pp 90-107.

Gefen, D., Ridgon, E., and Straub, D. "An Update and Extension to SEM Guidelines for Administrative and Social Science Research," MIS Quarterly (35:2) 2011, pp 3-16:A11A17.

Gefen, D., Straub, D., and Boudreau, M. "Structural Equation Modeling and Regression: Guidelines for Research Practice," Communications of AIS (4:7) 2000, pp 1-74.

Gorla, N., Somers, T., and Wong, B. "Organizational Impact of System Quality, Information Quality, and Service Quality," Journal of Strategic Information Systems (19) 2010, pp 207-228.

Gustavsson, M., and Jonsson, P. "Perceived Quality Deficiencies of Demand Information and Their Consequences," International Journal of Logistics Research and Applications: A Leading Journal of Supply Chain Management (11:4) 2008, pp 295-312.

Gustavsson, M., and Wanstrom, C. "Assessing information quality in manufacturing planning and control processes," International Journal of Quality \& Reliability Management (26:4) 2009, pp 325-340.

Hair, J., Ringle, C., and Sarstedt, M. "PLS-SEM: Indeed a Silver Bullet," Journal of Marketing Theory and Practice (19:2) 2011, pp 139-151.

Harrison, J., Hitt, M., Hoskisson, R., and Ireland, R. "Resource Complementarity in Business Combinations: Extending the Logic to Organizational Alliances," Journal of Management (27) 2001, pp 679-690.

Henseler, J., and Fassott, G. "Testing Moderating Effects in PLS Path Models: An Illustration of Available Procedures," in: Handbook of Partial Least Squares, V. Vinzi, W. Chin, J. Henseler and H. Wang (eds.), Springer-Verlag, Berlin, 2010, pp. 713-735.

Holsapple, C., and Wu, J. "An Elusive antecedent of Superior Firm Performance: The Knowledge Management Factor," Decision Support Systems (52:1) 2012, pp 271-283.

Hopwood, C. "Moderation and Mediation in Structural Equation Modeling: Applications for Early Intervention Research," Journal of Early Intervention (29:3) 2007, pp 262-272.

Huner, K., Schierning, A., Otto, B., and Osterle, H. "Product Data Quality in Supply Chains: The Case of Beierdorf," Electronic Markets (21) 2011, pp 141-154.

Informs "Getting Started With Analytics: Analytics Success Stories," Informs, https://www.informs.org/Sites/Getting-Started-With-Analytics/Analytics-Success-Stories, 2013. 
Kannan, V., and Tan, K. "Just In Time, Total Quality Management, and Supply Chain Management: Understanding Their Linkages and Impact on Business Performance," Omega (33) 2005, pp 153-162.

Kaynak, H., and Hartley, J. "A Replication and Extension of Quality Management into the Supply Chain," Journal of Operations Management (26) 2008, pp 468-489.

Kim, H., Kim, Y., and Park, C. "Integration of Firm's Resource and Capability to Implement Enterprise CRM: A Case Study of a Retail Bank in Korea," Decision Support Systems (48:2) 2012, pp 313-322.

Kock, N. "Advanced Mediating Effects Tests, Multi-group Analyses, and Measurement Model Assessments in PLS-based SEM," in: ScriptWarp Systems , Laredo, Texas, 2013, pp. 114.

Kohli, R., and Grover, V. "Business value of IT: An essay on expanding research directions to keep up with the times," Journal of Association for Information Systems (9:1) 2008, pp 23-39.

Luo, J., Fan, M., and Zhang, H. "Information Technology and Organizational Capabilities: A Longitudinal Study of the Apparel Industry," Decision Support Systems (53) 2012, pp 186-194.

Melville, N., Kraemer, K., and Gurbaxani, V. "Review: Information Technology and Organizational Performance: An Integrative Model of IT Business Value," MIS Quarterly (28:2) 2004, pp 283-322.

Muller, D., Judd, C., and Yzerbyt, V. "When Moderation is mediated and Mediation is Moderated," Journal of Personality and Social Psychology (89:6) 2005, pp 852-863.

Nair, A. "Meta-analysis of the Relationship between Quality Management Practices and Firm Performance-implications for Quality Management Theory Development," Journal of Operations Management (24) 2006, pp 948-975.

Nunnally, J., and Bernstein, I. Psychometric Theory McGraw-Hill, New York, 1994.

O'Dwyer, J., and Renner, R. "The Promise of Advanced Supply Chain Analytics," Supply Chain Management Review (15) 2011, pp 32-37.

Oliva, R., and Watson, N. "Cross Functional Alignment in Supply Chain Planning: A Case Study of Sales \& Operations Planning," Journal of Operations Management (29:5) 2011, pp 434-448.

Peng, D., and Lai, F. "Using partial least squares in operations management research: A practical guideline and summary of past research," Journal of Operations Management (30) 2012, pp 467-480.

Petersen, K., Ragatz, G., and Monczka, R. "An Examination of Collaborative Planning Effectiveness and Supply Chain Performance," Journal of Supply Chain Management (41:2) 2005, pp 14-25.

Popovic, A., Hackney, R., Coelho, P., and Jaklic, J. "Towards business intelligence systems success: Effects of maturity and culture on analytical decision making," Decision Support Systems (In Press) 2012.

Redman, T. "Improve Data Quality for Competitive Advantage," Sloan Management Review (36:2) 1995, pp 99-107.

Redman, T. "The Impact of Poor Data Quality on the Typical Enterprise," Communications of the $A C M(41: 2) 1998$, pp 79-82.

Rungtusanatham, M. "Beyond Improved Quality: The Motivational Effects of Statistical Process Control," Journal of Operations Management (19) 2001, pp 653-673. 
Shang, J., Tadikamalla, P., Kirsch, L., and Brown, L. "A Decision Support System for Managing Inventory at GlaxoSmithKline," Decision Support Systems (46) 2008, pp 1-13.

Shapiro, J. Modeling the Supply Chain, (2nd ed.) Dexbury Press, 2007.

Sharma, R., Reynolds, P., Scheepers, R., and Seddon, P. "Business Analytics and Competitive Advantage: A Review and a Research Agenda," in: Bridging the Socio-technical Gap in Decision Support Systems, A. REspicio (ed.), IOS Press, 2010.

Singh, N. "Emerging Technologies to Support Supply Chain Management," Communications of the ACM (46:9) 2003, pp 243-247.

Teece, D., Pisano, G., and Shuen, A. "Dynamic Capabilities and Strategic Management," Strategic Management Journal (18:7) 1997, pp 509-533.

Thibodeau, P. "The Top 10 Tech Priorities of CIOs," Computerworld, http://www.computerworld.com/s/article/9223502/The top 10 tech priorities of CIOs (Jan 18) 2012.

Trkman, P., McCormack, K., de Oliveira, M., and Ladeira, M. "The Impact of Business Analytics on Supply Chain Performance," Decision Support Systems (49:3) 2010, pp 318327.

Turban, E., Sharda, R., Delen, D., and King, D. Business Intelligence: A Managerial Approach, (2 ed.) Prentice Hall, New York, 2011.

Vollmann, T., Berry, W., Whybark, D., and Jacobs, F. Manufacturing Planning and Control for Supply Chain Management, (5th ed.) McGraw Hill, 2005.

Wacker, J. "A definition of theory: research guidelines for different theory-building research methods in operations management," Journal of Operations Management (16:4) 1998, pp 361-385.

Wacker, J., and Sheu, C. "Effectiveness of Manufacturing Planning and Control Systems on Manufacturing Competitiveness: Evidence from Global Manufacturing Data," International Journal of Production Research (44:1) 2006, pp 1015-1036.

Wade, M., and Hulland, J. "The Resource-based View and Information Systems Research: Review, Extension, and Suggestions for Future Research," MIS Quarterly (28:1) 2004, pp 107-142.

Whybark, D., Wacker, J., and Sheu, C. "The Evolution of an International Academic Manufacturing Survey," Decision Line (May) 2009, pp 17-19. 